\title{
BALANÇO DE CARBONO E NUTRIENTES EM PLANTIO PURO E MISTO DE ESPÉCIES FLORESTAIS NATIVAS NO SUDESTE DA BAHIA ${ }^{(1)}$
}

\author{
Antonio Carlos da Gama-Rodrigues ${ }^{(2)}$, Emanuela Forestieri da \\ Gama-Rodrigues ${ }^{(2)} \&$ Nairam Félix de $\operatorname{Barros}^{(3)}$
}

\begin{abstract}
RESUMO
A manutenção da produção florestal depende da quantidade e do fluxo de nutrientes no ecossistema, os quais são afetados pelas técnicas de manejo utilizadas. $\mathrm{O}$ objetivo deste trabalho foi avaliar diferenças na ciclagem e no balanço de $\mathbf{C} \mathrm{e}$ nutrientes, em plantio puro e misto de espécies florestais nativas, bem como em fragmentos florestais de Mata Atlântica. O trabalho foi desenvolvido em solos de tabuleiro do sudeste da Bahia, Brasil, no período de agosto de 1994 a julho de 1995, em plantios, com 22 anos de idade, de pau-roxo, Peltogyne angustiflora; putumuju, Centrolobium robustum; arapati, Arapatiella psilophylla; arapaçu, Sclerolobium chrysophyllum; claraíba, Cordia trichotoma; e óleo-comumbá, Macrolobium latifolium. Como referências, foram utilizadas uma floresta secundária, praticamente em estado clímax, e uma capoeira de 40 anos de idade. As quantidades totais de carbono e nutrientes no sistema (solo + parte aérea + serapilheira) variou marcadamente entre as espécies florestais. $O$ plantio misto apresentou maior acúmulo desses elementos do que os plantios puros. $O$ plantio misto apresentou maior intensidade de ciclagem bioquímica para todos os nutrientes do que a média dos plantios puros. Resultado similar ocorreu para a ciclagem biogeoquímica, à exceção de $\mathrm{Ca}$. $\mathrm{O}$ balanço de $\mathrm{C}, \mathrm{P} \mathrm{e} \mathrm{K}$ foi negativo em todas as coberturas florestais; entretanto, para $\mathrm{N}$ o balanço foi positivo. $\mathrm{O}$ balanço de $\mathrm{Ca}$ foi positivo apenas para o arapaçu, enquanto o de Mg foi negativo somente no putumuju e óleo-comumbá. $\mathrm{O}$ balanço mais negativo foi de $\mathrm{P}$, seguido de $\mathrm{K}$ e Ca. O plantio misto apresentou balanço próximo à média dos plantios puros. Desse modo, o plantio misto mostrouse mais adequado, por proporcionar, simultaneamente, maior eficiência da ciclagem bioquímica e biogeoquímica e balanços mais equilibrados de carbono e nutrientes.
\end{abstract}

Termos de indexação: Mata Atlântica, ciclos bioquímico e biogeoquímico.

\footnotetext{
(1) Recebido para publicação em fevereiro de 2007 e aprovado em fevereiro de 2008.

(2) Professor Associado do Laboratório de Solos, Centro de Ciências e Tecnologias Agropecuárias (CCTA), Universidade Estadual do Norte Fluminense Darcy Ribeiro - UENF. CEP 28013-602 Campos dos Goytacazes (RJ). E-mail: tonygama@uenf.br; emanuela@uenf.br

${ }^{(3)}$ Professor Titular do Departamento de Solos, Universidade Federal de Viçosa - UFV. CEP 36570-000 Viçosa (MG). Bolsista do CNPq. E-mail: nfbarros@ufv.br
} 


\title{
SUMMARY: CARBON AND NUTRIENT BALANCE IN PURE AND MIXED STANDS OF NATIVE TREE SPECIES IN SOUTHEASTERN BAHIA, BRAZIL
}

\begin{abstract}
This study aimed to evaluate the differences in carbon and nutrient cycling and balance in two plantation systems of forest species native in the Atlantic Forest. The plantation systems consisted of 22 year-old mixed stand and pure stands of six hardwood species (Peltogyne angustiflora, Centrolobium robustum, Arapatiella psilophylla, Sclerolobium chrysophyllum, Cordia trichotoma, Macrolobium latifolium) native to the southeastern region of Bahia, Brazil, that were evaluated from August 1994 through July 1995. As references, the study included a natural forest and a 40-year-old, naturally regenerating secondary forest. Total stocks of carbon and nutrients in the soil-plant-litter systems varied among species in pure stands, but the capacity of accumulation of these elements in the mixed stands was greater than in the pure stands. The intensity of biochemical cycling of all studied nutrients in mixed stands was greater than the average values observed for pure stands. A similar result was obtained for biogeochemical cycling, with exception of $C a$. The $C, P, K$ balances were negative for all forest species, whereas the $N$ balance was positive. The Ca balance was only positive in the pure stand of Sclerolobium chrysophyllum, and the $\mathrm{Mg}$ balance was negative only in the pure stands of Centrolobium robustum and Macrolobium latifolium. The most negative balances were found for $P, K$ and $C a$. The mean carbon and nutrient balances in the mixed-tree stands were similar to those in pure stands. The biochemical and biogeochemical cycling in mixed-tree stands was more efficient and the balance more equilibrated than in pure stands. Therefore, mixed-tree stands proved to be the best plantation system, in view of the more efficient biochemical and biogeochemical cycling and better balanced of carbon and nutrients.
\end{abstract}

Index terms: Atlantic forest, biochemical and biogeochemical cycling.

\section{INTRODUÇÃO}

Os solos das regiões tropicais são em geral muito ácidos e de baixa fertilidade. Esses apresentam potencial relativamente alto de lixiviação de nutrientes (por exemplo, $\mathrm{NO}_{3}$ e K) e elevada capacidade de fixação de fósforo. A maior parte das florestas naturais dos trópicos úmidos e subúmidos crescem sobre estes tipos de solos. A alta produção de biomassa dessas florestas e sua manutenção exigem elevadas quantidades de nutrientes. Parte desses nutrientes, depois de certa fase de desenvolvimento da floresta, é suprida pelo processo de ciclagem, cuja dinâmica e magnitude de contribuição variam com o ecossistema florestal.

Nessas condições edafoclimáticas, a compreensão dos mecanismos de ciclagem de nutrientes na floresta permitiria sua exploração, mediante manejo para colheita de madeira ou outros produtos, bem como o estabelecimento de sistemas de produção vegetal sustentáveis, sobretudo de sistemas florestais ou agroflorestais que formam uma estrutura que muito se assemelha à da vegetação natural (O'Connell \& Sankaran, 1997; Nair, 2006), por meio de um manejo que otimize o processo de ciclagem de nutrientes. Nesse contexto, o solo deixa de ser apenas um meio de produção para também ser considerado o componente central mediador dos processos que ocorrem no ecossistema florestal.
O processo de ciclagem de nutrientes pode ser avaliado de acordo com o objetivo do estudo. Três ciclos compõem o processo: o geoquímico, que envolve os processos de entrada e saída de nutrientes no ecossistema; o biogeoquímico, que consiste dos processos de transferência de nutrientes entre o solo e as plantas; e o bioquímico, que se refere à retranslocação de nutrientes dentro da planta (Switzer \& Nelson, 1972).

A comparação do processo de ciclagem de carbono e nutrientes em florestas plantadas com o de floresta natural permite avaliar possíveis alterações decorrentes de técnicas de manejo aplicadas e inferir sobre a sustentabilidade dos sítios florestais. Em solos de baixa fertilidade, as quantidades de carbono e nutrientes encontradas no solo, na serapilheira e na biomassa aérea são importantes na definição do balanço de nutrientes e podem servir de indicadores de diferenças entre espécies e, ou, sistemas florestais, em especial no que tange à disponibilidade de nutrientes para as plantas, e, portanto, da eventual necessidade de aplicação de fertilizantes (GamaRodrigues \& Barros, 2002; Zaia \& Gama-Rodrigues, 2004; Cunha et al., 2005). Estudos desse tipo poderiam ainda fornecer subsídios para desenvolvimento de técnicas de manejo que sejam ecológica e economicamente viáveis.

O objetivo deste trabalho foi avaliar diferenças na ciclagem e no balanço de carbono e nutrientes em 
plantio puro e misto de espécies florestais nativas e em fragmentos florestais de Mata Atlântica na região dos tabuleiros costeiros do sudeste da Bahia.

\section{MATERIAL E MÉTODOS}

O trabalho foi realizado no arboreto da Estação Ecológica do Pau-Brasil (ESPAB), Porto Seguro, Bahia, Brasil ( $16^{\circ} 23^{\prime} \mathrm{S}$ e $\left.39^{\circ} 11^{\prime} \mathrm{W}\right)$. A floresta natural foi classificada como "Floresta Ombrófila Densa das Terras Baixas" (Veloso et al., 1991). Estrutural e fisionomicamente, essa vegetação muito se assemelha à da Floresta Amazônica (Mori \& Silva, 1980). De acordo com o sistema Köppen, o clima é classificado como Af, caracterizado por uma pluviosidade média anual de $1.696 \mathrm{~mm}$, sem estação seca definida, e a temperatura média anual é de $23^{\circ} \mathrm{C}$, com máxima de $30{ }^{\circ} \mathrm{C}$ e mínima de $20^{\circ} \mathrm{C}$ (Vinha \& Lobão, 1989). O solo é um Argissolo Amarelo Tb álico, fortemente ácido e de fertilidade natural muito baixa (Leão \& Melo, 1990).

As espécies estudadas foram: pau-roxo, Peltogyne angustiflora; putumuju, Centrolobium robustum (Vell.) Mart.; arapati, Arapatiella psilophylla (Harms.) Cowan; arapacu, Sclerolobium chrysophyllum Loep \& Endl; claraíba, Cordia trichotoma (Vell.) Arrab.; e óleo-comumbá, Macrolobium latifolium Vog. O plantio foi realizado em parcelas puras fixas de $144 \mathrm{~m}^{2}$ sem repetição, sem adubação, no espaçamento de $2 \times 2 \mathrm{~m}$, totalizando 36 árvores por espécie. As avaliações foram feitas no período de agosto de 1994 a julho de 1995. Tais espécies também foram estudadas em plantio misto, associadas com outras 57 espécies nativas e exóticas, no mesmo espaçamento dos plantios puros, em parcela de $5.320 \mathrm{~m}^{2}$, totalizando 1.330 árvores plantadas aleatoriamente com diferentes freqüências para cada espécie. A idade, em ambos os sistemas de plantio, era de 22 anos na época das amostragens.

O diâmetro (DAP) e a altura das árvores foram medidos. Após isso, a biomassa da parte aérea (folhas, galhos, casca e lenho - dados não publicados) foi quantificada de árvores com dimensões próximas da média da população de cada espécie. No plantio misto, procurou-se para cada espécie a árvore com diâmetro, formato de fuste e copa mais similares à da árvore de dimensões médias do plantio puro (Gama-Rodrigues et al., 2007). Visou-se, assim, caracterizar árvores mais similares nos dois sistemas de plantio. Assumiuse que cada espécie amostrada no plantio misto representaria a média do "stand" como um todo, pois a variação de biomassa aérea entre as espécies foi de apenas $18 \%$. Nesse sentido, os resultados de biomassa do "stand" corresponderam à média das espécies amostradas. A produção de folhedo (folhas já descartadas pelas árvores com diferentes estádios de senescência) foi avaliada quinzenalmente em coletores de $0,25 \mathrm{~m}^{2}$ com tela de $1 \mathrm{~mm}$ de malha (náilon), colocados a $0,5 \mathrm{~m}$ de altura do solo. Nos plantios puros, utilizaram-se quatro coletores e, no plantio misto, vinte e quatro coletores em seis subparcelas de $100 \mathrm{~m}^{2}$, tendo como ponto de referência as espécies dos plantios puros. A amostragem da serapilheira acumulada (material depositado sobre o solo e com diferentes graus de decomposição) foi feita trimestralmente, utilizando-se de um quadrado de madeira de $0,25 \mathrm{~m}^{2}$, com quatro repetições. As folhas perfizeram mais de $95 \%$ da massa da serapilheira em todas as coberturas florestais, caracterizando, assim, uma serapilheira predominantemente foliar (dados não publicados).

Nas amostras, determinaram-se os teores de $\mathrm{P}$ (colorimetricamente, pelo método do complexo fosfomolíbdico, reduzido com ácido ascórbico, modificado por Braga \& Defelipo, 1974), de K (fotometria de chama), de Ca e Mg (espectrofotometria de absorção atômica), após digestão nítrico-perclórica, e de N, pelo método Kjeldahl, descritos por Bataglia et al. (1983). $\mathrm{O}$ teor de $\mathrm{C}$ foi obtido por queima total de $1 \mathrm{~g}$ de material vegetal, a $550^{\circ} \mathrm{C}$, em mufla, considerando sua concentração como $500 \mathrm{~g} \mathrm{~kg}^{-1}$ da matéria orgânica livre de cinzas, conforme procedimento adotado por Taylor et al. (1989) e van Wesemael (1993).

Os resultados foram referidos para massa seca em estufa a $65^{\circ} \mathrm{C}$ até peso constante. Com os dados de teor de nutrientes e biomassa, calculou-se o conteúdo de carbono e nutrientes.

O solo sob os plantios (puro e misto) foi caracterizado quimicamente em quatro amostras compostas (15 simples/composta), coletadas em ziguezague nas linhas e entrelinhas de plantio, nas profundidades de $0-5,5-10,10-20,20-30$ e $30-50 \mathrm{~cm}$, conforme os métodos descritos por Embrapa (1997): pH (água); $\mathrm{P}$ e K extraíveis por Mehlich-1; Ca e Mg trocáveis por $\mathrm{KCl} 1 \mathrm{~mol} \mathrm{~L}^{-1}$; C orgânico por oxidação com $\mathrm{K}_{2} \mathrm{Cr}_{2} \mathrm{O}_{7} 0,4 \mathrm{~mol} \mathrm{~L}^{-1}$; e $\mathrm{N}$ total pelo método Kjeldahl. No cálculo da quantidade de C e nutrientes no perfil $(0-50 \mathrm{~cm})$, considerou-se a densidade aparente do solo de cada camada amostrada. Os valores de densidade foram obtidos de perfis modais, na própria ESPAB, descritos por Cadima (1984). Em cada camada amostrada, a densidade foi de 1,$20 ; 1,25 ; 1,30$; 1,50; e 1,45 kg dm${ }^{-3}$, respectivamente.

Amostras de folhedo, de serapilheira e de solo de uma Floresta Ombrófila Densa Secundária, praticamente em estado clímax, e de uma capoeira de, aproximadamente, 40 anos de idade, foram coletadas de modo semelhante ao plantio puro e misto, em uma única parcela fixa de $500 \mathrm{~m}^{2}$ e analisadas como referencial aos outros sistemas. Como a ESPAB é uma reserva florestal não foi possível fazer amostragem destrutiva das árvores nas áreas de floresta natural e de capoeira. Assim, a quantidade de $\mathrm{C}$ e nutrientes na biomassa aérea foram estimadas, assumindo-se que a taxa de reposição desses elementos via folhedo nessas florestas naturais seria similar à do plantio misto, de maneira análoga à produção de biomassa de folhedo, e que também o plantio misto foi 
similar a essas duas florestas naturais em relação à concentração de nutrientes na parte aérea (GamaRodrigues et al., 2007). A taxa de reposição foi obtida pela seguinte expressão: Taxa de reposição $(\mathrm{TR} ; \%)=$ (conteúdo no folhedo/conteúdo na parte aérea) x 100. No plantio misto, as taxas de $\mathrm{C}, \mathrm{N}, \mathrm{P}, \mathrm{K}, \mathrm{Ca}$ e $\mathrm{Mg}$ foram de 2,$0 ; 13,4 ; 4,5 ; 3,1 ; 3,4$ e 7,7 \% respectivamente.

Para o balanço interno de nutrientes, tomaram-se valores dos conteúdos dos nutrientes no solo (em diferentes profundidades), na serapilheira acumulada e na parte aérea das árvores, para cada cobertura florestal. O balanço interno de nutrientes foi obtido pela seguinte expressão:

\section{Balanço interno de nutrientes $=$ solo $-($ parte aérea + serapilheira)}

Desse modo, o balanço interno de nutrientes expressaria a diferença de estoque entre o solo e a vegetação aérea.

A intensidade do processo de ciclagem bioquímica foi avaliada pelas variações percentuais nas concentrações de nutrientes entre folhas da parte aérea (F) e folhedo (Fo), em que valores negativos indicam que houve retranslocação de nutrientes. Já as variações percentuais nas concentrações de nutrientes entre o folhedo ( $\mathrm{F}$ ) e a serapilheira foliar (S) indicaram a intensidade de ciclagem biogeoquímica dos nutrientes contidos na serapilheira, em que valores negativos indicam o predomínio da mineralização quanto à imobilização (Zaia \& Gama-Rodrigues, 2004; Cunha et al., 2005). Tal fato, portanto, indicaria o potencial de mineralização, considerando a possibilidade de tal ocorrência durante o processo de decomposição da serapilheira (Adams \& Attiwill, 1986). Assim, a ciclagem foi estimada a partir da seguinte expressão:

\section{Ciclagem bioquímica (folhedo vs folhas $)=$ $\{([\mathrm{Fo}]-[\mathrm{F}]) /[\mathrm{F}]\} \times 100$}

$$
\begin{gathered}
\text { Ciclagem biogeoquímica } \\
\text { (serapilheira vs folhedo) }=\{([\mathrm{S}]-[\mathrm{Fo}]) /[\mathrm{Fo}]\} \times 100
\end{gathered}
$$

Os dados de estoques dos compartimentos (parte aérea, folhedo, serapilheira e solo), dos ciclos e do balanço interno de carbono e nutrientes das coberturas florestais foram submetidos à análise de componentes principais, que possibilita sintetizar a variação multidimensional dos dados analisados em um diagrama, ordenando-os nos eixos, de acordo com suas similaridades em torno das variáveis utilizadas (Ter Braak, 1986). A análise por componentes principais consiste em transformar um conjunto original de variáveis em outro conjunto de dimensão equivalente. Cada componente principal é uma combinação linear das variáveis originais. Além disso, os componentes principais são independentes entre si e estimados com o propósito de reter, em ordem de estimação, o máximo de informação em termos de variação total contida nos dados iniciais (Cruz \& Regazzi, 1997). A carga associada aos componentes principais é o valor que representa a contribuição relativa de cada componente para explicar a variação total dos dados. Desse modo, considerou-se o valor de carga $>0,5$ e $<0,7$ como de baixa associação para a interpretação dos componentes principais (Wick et al., 1998). O número de componentes utilizados para explicar a variação dos dados pode igualar-se ao número de variáveis, porém os eixos posteriores contribuem cada vez menos para explicar os dados. No caso do presente trabalho, usaram-se os três primeiros componentes considerados suficientes para explicar os dados referentes às cargas relativas das diferentes variáveis associadas aos componentes principais. Contudo, na dispersão gráfica, foram utilizados apenas os dois primeiros componentes pela facilidade de interpretação de um gráfico em duas dimensões (Gomes et al., 2004).

\section{RESULTADOS E DISCUSSÃO}

\section{Plantios puro e misto}

\section{Estoque de carbono e nutrientes}

As espécies florestais apresentaram distinta capacidade de acumulação de $\mathrm{C}$ e nutrientes no sistema solo-planta (Quadro 1). Na parte aérea dos plantios puros, a acumulação média de $\mathrm{C}$ foi de aproximadamente $125.233 \mathrm{~kg} / \mathrm{ha}(\mathrm{CV} 21,0 \%)$, de N $801 \mathrm{~kg} \mathrm{ha}^{-1}$ (CV 14,9 \%), de P $50 \mathrm{~kg} \mathrm{ha}^{-1}$ (CV 33,7 \%), de K $534 \mathrm{~kg} \mathrm{ha}^{-1}$ (CV 26,3 \%), de Ca $2.230 \mathrm{~kg} \mathrm{ha}^{-1}$ (CV 40,7 \%), de Mg $169 \mathrm{~kg} \mathrm{ha}^{-1}$ (CV 43,7 \%). Verifica-se que a menor variação ocorreu para $\mathrm{N}$ e a maior para $\mathrm{Mg}$. Por outro lado, Ca foi o elemento de maior acumulação na biomassa aérea, seguido do $\mathrm{N}, \mathrm{K}, \mathrm{Mg}$ e $\mathrm{P}$. Resultados similares foram encontrados em plantios comerciais de eucalipto e dandá em solos de tabuleiro no sul da Bahia (Gama-Rodrigues \& Barros, 2002). $\mathrm{O}$ plantio misto acumulou em relação à média dos plantios puros para $\mathrm{C}+38,4 \% ; \mathrm{N}+40,6 \% ; \mathrm{P}+12 \%$; $\mathrm{K}+21,3 \% ; \mathrm{Ca}+4,3 \% ; \mathrm{Mg}+60,9 \%$. Esses resultados indicam que o plantio misto tenderia a promover maior acúmulo de nutrientes na biomassa aérea, especialmente de $\mathrm{C}, \mathrm{N}$ e $\mathrm{Mg}$. As coberturas florestais foram distribuídas em cinco grupos heterogêneos entre si, pela análise de componentes principais. Três componentes principais foram necessários para explicar $80 \%$ da variância total entre os plantios. O primeiro componente principal (CP1) explicou 41,5\% da variação total; o segundo componente (CP2), 31,8 \%, e o terceiro componente (CP3), $18,8 \%$. As variáveis mais associadas ao $\mathrm{CP} 1$ foram $\mathrm{K}, \mathrm{C}$ e $\mathrm{P}$, nessa ordem; enquanto o $\mathrm{Mg}$ esteve associado ao CP2 e $\mathrm{Ca}$ ao $\mathrm{CP} 3$; já o $\mathrm{N}$ apresentou baixa associação $(<0,70)$ aos três componentes (Quadro 2). Esses resultados revelam que as principais variáveis na distinção dos plantios florestais foram K, C e P. O grupo de maior número de indivíduos foi formado pelo arapati, arapaçu e claraíba. O pau-roxo, putumuju e óleo-comumbá 
Quadro 1. Conteúdo de nutrientes na parte aérea, na serapilheira e no solo (camada 0-50 cm), em valores absolutos e percentuais em plantio puros e mistos de espécies florestais no sudeste da Bahia

\begin{tabular}{|c|c|c|c|c|c|c|c|c|c|c|c|c|c|c|c|c|c|c|}
\hline \multirow{2}{*}{$\operatorname{Cob}^{(1)}$} & \multicolumn{6}{|c|}{ Parte aérea } & \multicolumn{6}{|c|}{ Serapilheira } & \multicolumn{6}{|c|}{ Solo } \\
\hline & C & $\mathbf{N}$ & $\mathbf{P}$ & $\mathbf{K}$ & $\mathbf{C a}$ & Mg & C & $\mathbf{N}$ & $\mathbf{P}$ & $\mathbf{K}$ & $\mathbf{C a}$ & $\mathrm{Mg}$ & C & $\mathbf{N}$ & $\mathbf{P}$ & $\mathbf{K}$ & $\mathbf{C a}$ & $\mathrm{Mg}$ \\
\hline & \multicolumn{18}{|c|}{$-\mathrm{kg} \mathrm{ha}{ }^{-1}$} \\
\hline 1 & 170.800 & 888 & 68 & 743 & 2.972 & 152 & 5.334 & 156 & 2,2 & 12 & 344 & 17 & 93.990 & 6.710 & 5,1 & 74 & 1.274 & 427 \\
\hline$\%$ & 63,2 & 11,5 & 90,3 & 89,6 & 64,7 & 25,5 & 2,0 & 2,0 & 2,9 & 1,4 & 7,5 & 2,9 & 34,8 & 86,5 & 6,8 & 8,9 & 27,8 & 71,6 \\
\hline 2 & 106.900 & 969 & 33 & 324 & 2.589 & 307 & 3.322 & 106 & 1,8 & 9 & 96 & 24 & 88.440 & 6.194 & 8,2 & 89 & 440 & 121 \\
\hline$\%$ & 53,8 & 13,3 & 76,7 & 76,8 & 82,8 & 67,9 & 1,7 & 1,5 & 4,2 & 2,1 & 3,1 & 5,3 & 44,5 & 85,2 & 19,1 & 21,1 & 14,1 & 26,8 \\
\hline 3 & 118.400 & 718 & 44 & 519 & 1.035 & 99 & 7.248 & 209 & 3,4 & 17 & 141 & 13 & 101.235 & 6.553 & 7,5 & 106 & 628 & 314 \\
\hline$\%$ & 52,2 & 9,6 & 80,1 & 80,8 & 57,4 & 23,2 & 3,2 & 2,8 & 6,2 & 2,6 & 7,8 & 3,1 & 44,6 & 87,6 & 13,7 & 16,5 & 43,8 & 73,7 \\
\hline 4 & 142.000 & 816 & 50 & 462 & 1.102 & 116 & 7.965 & 218 & 3,3 & 19 & 262 & 32 & 85.280 & 5.707 & 6,7 & 73 & 1.462 & 379 \\
\hline$\%$ & 60,4 & 12,1 & 83,3 & 83,4 & 39,0 & 22,0 & 3,4 & 3,2 & 5,5 & 3,4 & 9,3 & 6,1 & 36,3 & 84,7 & 11,2 & 13,2 & 52,7 & 71,9 \\
\hline 5 & 109.600 & 634 & 33 & 548 & 2.815 & 178 & 1.462 & 55 & 1,5 & 7 & 69 & 15 & 107.217 & 6.548 & 8,3 & 168 & 1.199 & 393 \\
\hline$\%$ & 50,2 & 8,8 & 77,1 & 75,8 & 68,9 & 30,4 & 0,7 & 0,8 & 3,5 & 1,0 & 1,7 & 2,6 & 49,1 & 90,5 & 19,4 & 23,2 & 29,4 & 67,1 \\
\hline 6 & 103.700 & 780 & 72 & 606 & 2.865 & 160 & 7.191 & 196 & 2,8 & 14 & 258 & 45 & 105.292 & 6.181 & 7,1 & 78 & 462 & 191 \\
\hline$\%$ & 48,0 & 10,9 & 87,9 & 86,8 & 79,9 & 40,4 & 3,3 & 2,7 & 3,4 & 2,0 & 7,2 & 11,4 & 48,7 & 86,4 & 8,7 & 11,2 & 12,9 & 48,2 \\
\hline 7 & 173.300 & 1.126 & 56 & 648 & 2.325 & 272 & 4.095 & 133 & 1,7 & 9 & 134 & 20 & 115.897 & 7.492 & 8,4 & 95 & 813 & 297 \\
\hline$\%$ & 59,1 & 12,9 & 84,7 & 86,2 & 71,1 & 46,2 & 1,4 & 1,5 & 2,6 & 1,2 & 4,1 & 3,4 & 39,5 & 85,6 & 12,7 & 12,6 & 24,8 & 50,4 \\
\hline 8 & 169.800 & 866 & 49 & 710 & 2.853 & 156 & 4.136 & 113 & 2,1 & 10 & 154 & 12 & 79.915 & 5.820 & 2,8 & 81 & 552 & 225 \\
\hline$\%$ & 66,9 & 12,7 & 90,9 & 88,6 & 80,2 & 39,7 & 1,6 & 1,7 & 3,9 & 1,2 & 4,3 & 3,1 & 31,5 & 85,6 & 5,2 & 10,1 & 15,5 & 57,3 \\
\hline 9 & 213.700 & 1.127 & 47 & 1.000 & 3.118 & 312 & 4.323 & 152 & 1,8 & 12 & 135 & 20 & 57.865 & 4.380 & 5,4 & 93 & 756 & 211 \\
\hline$\%$ & 77,5 & $1,9,9$ & 86,7 & 90,5 & 77,8 & 57,5 & 1,6 & 2,7 & 3,3 & 1,1 & 3,4 & 3,7 & 21,0 & 77,4 & 10,0 & 8,4 & 18,9 & 38,9 \\
\hline Média & 145.355 & 880 & 50 & 617 & 2.408 & 194 & 5008 & 148 & 2,3 & 12 & 177 & 22 & 92.792 & 6176 & 6,6 & 95 & 842 & 284 \\
\hline $\mathrm{CV}(\%)$ & 26,6 & 19,3 & 27,0 & 31,2 & 32,9 & 41,6 & 42,4 & 36,0 & 30,9 & 32,6 & 51,1 & 48,1 & 18,8 & 13,9 & 28,2 & 30,8 & 44,8 & 36,6 \\
\hline
\end{tabular}

(1) Coberturas: 1: Pau-roxo; 2: Putumuju; 3: Arapati; 4: Arapaçu; 5: Claraíba; 6: Óleo-comumbá; 7: Misto; 8: Capoeira; 9: Floresta natural.

constituíram grupos individuais. O plantio misto também constituiu um grupo individual, expressando a sua dissimilaridade em relação aos plantios puros (Figura 1a).

Houve alta variação entre os plantios puros no aporte de $\mathrm{C}$ e nutrientes via folhedo (Quadro 3). $\mathrm{O}$ aporte médio de $\mathrm{C}$ foi de $3.127 \mathrm{~kg} \mathrm{ha}^{-1}$ (CV 22,1\%); de $\mathrm{N} 113,8 \mathrm{~kg} \mathrm{ha}^{-1}$ (CV 23,6\%); de P 2,3 kg ha-1 (CV

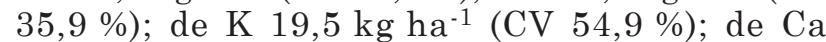
78,2 $\mathrm{kg} \mathrm{ha}^{-1}$ (CV 28,2\%); de Mg 16,0 kg ha ${ }^{-1}$ (CV $35,2 \%)$. Os maiores aportes de cada nutriente variaram de acordo com a espécie. Destaca-se para N o arapati; $\mathrm{P}$ o arapati e a claraíba; K a claraíba; Ca o arapaçu e a claraíba; Mg a claraíba. Esses resultados indicam que a claraíba promoveria os maiores aportes de nutrientes de acordo com a maior qualidade nutricional do folhedo (Quadro 4). O plantio misto variou em relação à média dos plantios puros para $\mathrm{C}$ $+12,2 \% ; \mathrm{N}+32,7 \% ; \mathrm{P}+8,7 \% ; \mathrm{K}+2,6 \% ; \mathrm{Ca}+$ $2,3 \% ; \mathrm{Mg}+31,3 \%$. Verifica-se, assim, que o misto tenderia a promover maiores aportes de nutrientes, especialmente para $\mathrm{Ne} \mathrm{Mg}$, do que os plantios puros. Os plantios florestais foram distribuídos em dois componentes principais (CP1 explicou 49,3\% da variância total e CP2 30,6 \%). O P, K e N foram as variáveis mais discriminantes na avaliação da variação total entre folhedos das diferentes coberturas florestais (Quadro 2). Foram constituídos cinco grupos heterogêneos entre si. O arapati, a claraíba e o misto constituíram grupos individuais, enquanto o pau-roxo e óleo-comumbá formaram um grupo e, o putumuju e arapaçu formaram outro grupo (Figura 1b).

As quantidades de $\mathrm{C}$ e nutrientes na serapilheira variaram entre os plantios florestais (Quadro 1). De maneira geral, Ca foi o elemento de maior acúmulo seguido do $\mathrm{N}, \mathrm{Mg}, \mathrm{K}$ e $\mathrm{P}$. Nos plantios puros, o acúmulo médio de $\mathrm{C}$ foi de $5.420 \mathrm{~kg} \mathrm{ha}^{-1}(\mathrm{CV} 47,4 \%)$, de $\mathrm{N} 157,0 \mathrm{~kg} \mathrm{ha}^{-1}$ (CV 41,3\%), de P 2,5 kg ha-1 (CV $31,6 \%$ ), de $\mathrm{K} 13,0 \mathrm{~kg} \mathrm{ha}^{-1}$ (CV 35,4\%), de Ca 195,0 kg ha-1 (CV 55,8\%), de Mg 24,4 kg ha-1 (CV $50,5 \%$ ). O plantio misto variou em relação à média dos plantios puros para $\mathrm{C}-24,5 \% ; \mathrm{N}-15,3 \%$; $32,0 \%$; K - 30,8\%; Ca - 31,3\%; Mg - 16,6\%. Resultado inverso daquele encontrado na parte aérea e no folhedo. As coberturas florestais foram distribuídas em cinco grupos heterogêneos entre si por dois componentes principais (CP1 explicou 74,6 \% da variância total e CP2 14,6 \%). As variáveis mais discriminantes na formação dos grupos heterogêneos foram C, N, K e P, estreitamente associadas ao CP1 (Quadro 2). Houve similaridade do plantio misto apenas com o putumuju. O arapaçu e óleo-comumbá formaram um grupo, enquanto pau-roxo, arapati e a claraíba constituíram grupos individuais (Figura 1c).

Analisando conjuntamente os três compartimentos da biomassa vegetal (parte aérea, folhedo e serapilheira), observa-se que a maior variabilidade (CV \%) entre os 
Quadro 2. Cargas relativas das diferentes variáveis associadas aos componentes principais (CP), nos compartimentos do sistema solo-planta, da ciclagem bioquímica e biogeoquímica e do balanço de $\mathrm{C}$ e nutrientes dos plantios puros e mistos. (Em negrito, cargas $>0,70$ usadas para interpretar cada componente principal)

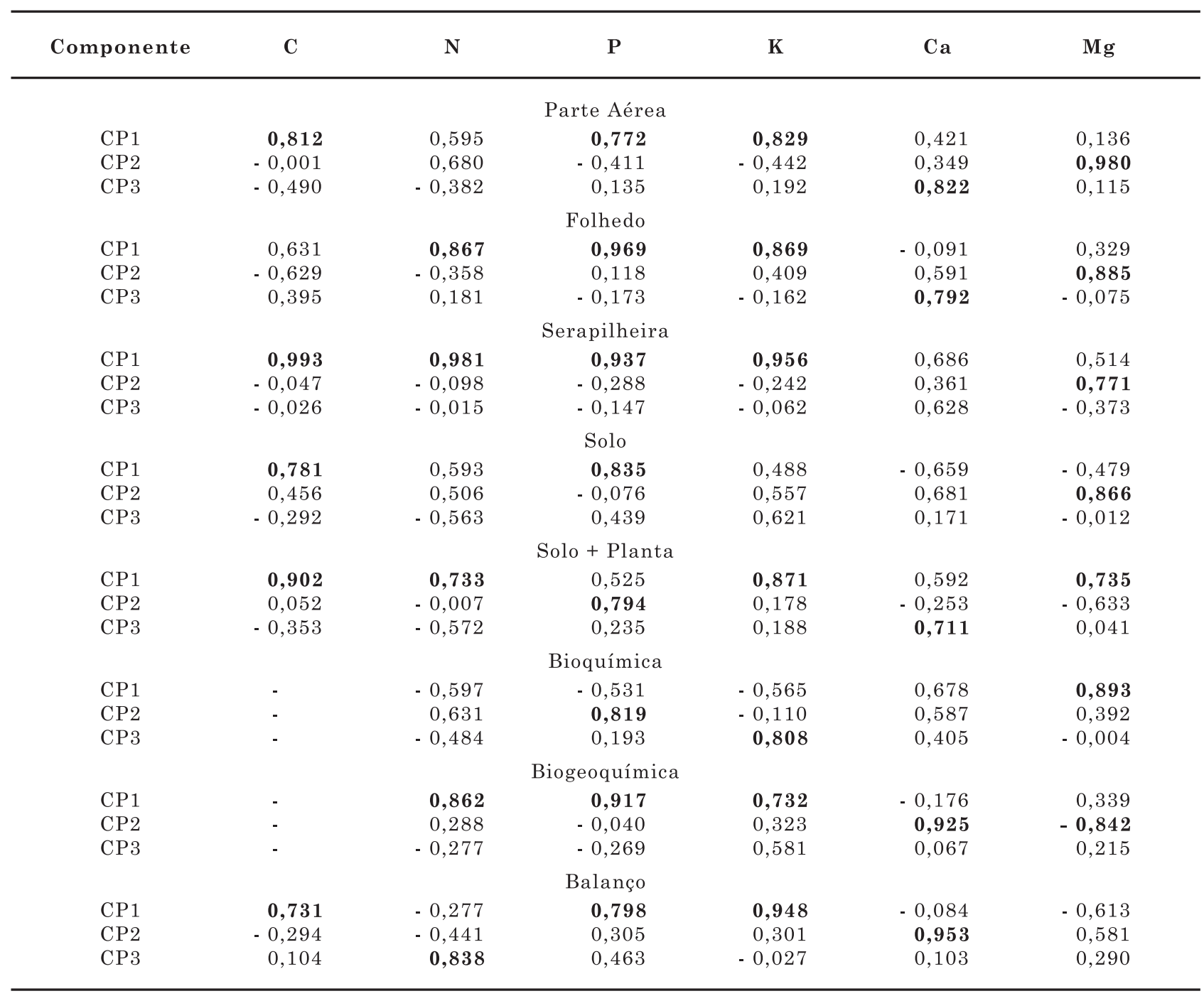

Quadro 3. Conteúdo de carbono e nutrientes no folhedo de diferentes coberturas florestais no sudeste da Bahia

\begin{tabular}{|c|c|c|c|c|c|c|}
\hline Cobertura & $\mathrm{C}$ & $\mathrm{N}$ & $\mathrm{P}$ & $\mathrm{K}$ & $\mathrm{Ca}$ & $\mathrm{Mg}$ \\
\hline & \multicolumn{6}{|c|}{$-\mathrm{kg} \mathrm{ha}^{-1}$ ano $^{-1}$} \\
\hline Pau-roxo & 2.663 & 92 & 1,3 & 10 & 98 & 12 \\
\hline Putumuju & 2.628 & 118 & 2,3 & 18 & 55 & 15 \\
\hline Arapati & 4.298 & 158 & 3,4 & 29 & 52 & 11 \\
\hline Arapaçu & 3.881 & 128 & 2,0 & 14 & 101 & 14 \\
\hline Claraíba & 2.681 & 114 & 3,2 & 38 & 101 & 28 \\
\hline Óleo-comumbá & 2.612 & 73 & 1,3 & 8 & 62 & 16 \\
\hline Misto & 3.507 & 151 & 2,5 & 20 & 80 & 21 \\
\hline Capoeira & 3.396 & 116 & 2,2 & 22 & 97 & 12 \\
\hline Floresta natural & 4.274 & 151 & 2,1 & 31 & 106 & 24 \\
\hline Média & 3.326 & 122 & 2,3 & 21 & 83 & 17 \\
\hline CV (\%) & 21,2 & 23,2 & 32,6 & 47,5 & 26,1 & 35,2 \\
\hline
\end{tabular}


Quadro 4. Concentração de carbono e nutrientes na folha, no folhedo e na serapilheira foliar de diferentes coberturas florestais no sudeste da Bahia

\begin{tabular}{|c|c|c|c|c|c|c|}
\hline Cobertura & C & $\mathbf{N}$ & $\mathbf{P}$ & $\mathbf{K}$ & $\mathrm{Ca}$ & $\mathrm{Mg}$ \\
\hline & \multicolumn{6}{|c|}{$-\mathrm{g} \mathrm{kg}^{-1}$} \\
\hline & \multicolumn{6}{|c|}{ Folha } \\
\hline Pau-roxo & 465 & 9,6 & 0,39 & 7,7 & 24,0 & 2,7 \\
\hline Putumuju & 480 & 23,2 & 0,86 & 9,3 & 9,5 & 3,3 \\
\hline Arapati & 480 & 12,2 & 0,50 & 7,9 & 4,5 & 1,7 \\
\hline Arapaçu & 485 & 13,6 & 0,48 & 7,5 & 7,5 & 1,4 \\
\hline Claraíba & 455 & 21,0 & 1,47 & 16,4 & 19,0 & 6,0 \\
\hline Óleo-comumbá & 480 & 14,1 & 0,72 & 7,0 & 8,0 & 2,9 \\
\hline Misto & 465 & 18,5 & 1,00 & 10,0 & 15,9 & 3,9 \\
\hline Capoeira & 470 & 12,9 & 1,30 & 8,7 & 15,4 & 3,9 \\
\hline Floresta natural & 470 & 16,3 & 0,70 & 11,8 & 15,3 & 4,5 \\
\hline Média & 472 & 15,7 & 0,82 & 9,6 & 13,2 & 3,4 \\
\hline \multirow[t]{2}{*}{$\mathrm{CV}(\%)$} & 2,1 & 28,2 & 45,3 & 30,8 & 47,5 & 42,1 \\
\hline & \multicolumn{6}{|c|}{ Folhedo } \\
\hline Pau-roxo & 468 & 16,2 & 0,23 & 1,75 & 17,2 & 2,11 \\
\hline Putumuju & 483 & 21,7 & 0,42 & 3,31 & 10,1 & 2,76 \\
\hline Arapati & 483 & 17,6 & 0,38 & 3,26 & 5,8 & 1,24 \\
\hline Arapaçu & 477 & 15,7 & 0,25 & 1,72 & 12,4 & 1,72 \\
\hline Claraíba & 463 & 19,7 & 0,55 & 6,56 & 17,4 & 4,84 \\
\hline Óleo-comumbá & 470 & 13,1 & 0,23 & 1,44 & 11,2 & 2,88 \\
\hline Misto & 474 & 20,4 & 0,33 & 2,70 & 10,8 & 2,84 \\
\hline Capoeira & 465 & 15,9 & 0,30 & 3,01 & 13,3 & 1,64 \\
\hline Floresta natural & 475 & 16,8 & 0,23 & 3,45 & 11,8 & 2,67 \\
\hline Média & 473 & 17,5 & 0,32 & 3,02 & 12,2 & 2,52 \\
\hline \multirow[t]{2}{*}{$\mathrm{CV}(\%)$} & 1,5 & 15,5 & 33,8 & 50,7 & 29,2 & 41,9 \\
\hline & \multicolumn{6}{|c|}{ Serapilheira Foliar } \\
\hline Pau-roxo & 420 & 12,2 & 0,17 & 1,01 & 27,3 & 1,37 \\
\hline Putumuju & 455 & 14,3 & 0,26 & 1,24 & 13,1 & 3,28 \\
\hline Arapati & 480 & 13,6 & 0,23 & 1,32 & 9,3 & 0,93 \\
\hline Arapaçu & 450 & 12,2 & 0,19 & 1,09 & 14,9 & 1,80 \\
\hline Claraíba & 430 & 16,8 & 0,47 & 2,39 & 21,7 & 4,74 \\
\hline Óleo-comumbá & 470 & 12,4 & 0,19 & 1,00 & 16,7 & 2,98 \\
\hline Misto & 450 & 14,9 & 0,19 & 1,04 & 14,9 & 2,24 \\
\hline Capoeira & 440 & 11,8 & 0,23 & 1,18 & 16,3 & 1,41 \\
\hline Floresta natural & 455 & 16,3 & 0,19 & 1,22 & 14,1 & 2,08 \\
\hline Média & 450 & 13,8 & 0,24 & 1,28 & 16,5 & 2,31 \\
\hline $\mathrm{CV}(\%)$ & 4,1 & 13,5 & 37,0 & 33,9 & 31,7 & 51,2 \\
\hline
\end{tabular}

plantios florestais ocorreu na serapilheira. Isto indica que os processos de decomposição e mineralização seriam bastante distintos entre as espécies e, ou, entre os sistemas de plantio (puro e misto). Para essas mesmas espécies e para os dois sistemas de plantio do presente trabalho, Gama-Rodrigues et al. (2003) encontraram diferenças significativas entre as taxas de decomposição da serapilheira foliar, mediante o uso da técnica de sacos de decomposição - litter bag.

As quantidades de $\mathrm{C}$ e nutrientes no solo variaram entre os plantios florestais, especialmente para $\mathrm{Ca}(\mathrm{CV}$ 46,2 \%), Mg (CV 37,0 \%) e K (CV 34,0 \%). Para C, N e $\mathrm{P}$ a variação entre as coberturas foi inferior a $20,0 \%$
(Quadro 1). No estoque de $\mathrm{C}$ e N, destaca-se o plantio misto; $\mathrm{P}$ plantio misto, putumuju e claraíba; $\mathrm{K}$ claraíba; Ca arapaçu, pau-roxo e claraíba; Mg pauroxo. Segundo tais resultados, nenhuma dessas coberturas apresentou maiores estoques de C e nutrientes como um todo. Contudo, destaca-se o fato de o plantio misto ter acumulado maiores quantidades de $\mathrm{C}$ e nutrientes na biomassa aérea do que a média dos plantios puros, sem que isso acarretasse menor nível de fertilidade do solo (Quadro 1). Houve dissimilaridade entre os plantios florestais com a formação de quatro grupos heterogêneos entre si, sendo necessários três componentes principais para explicar 

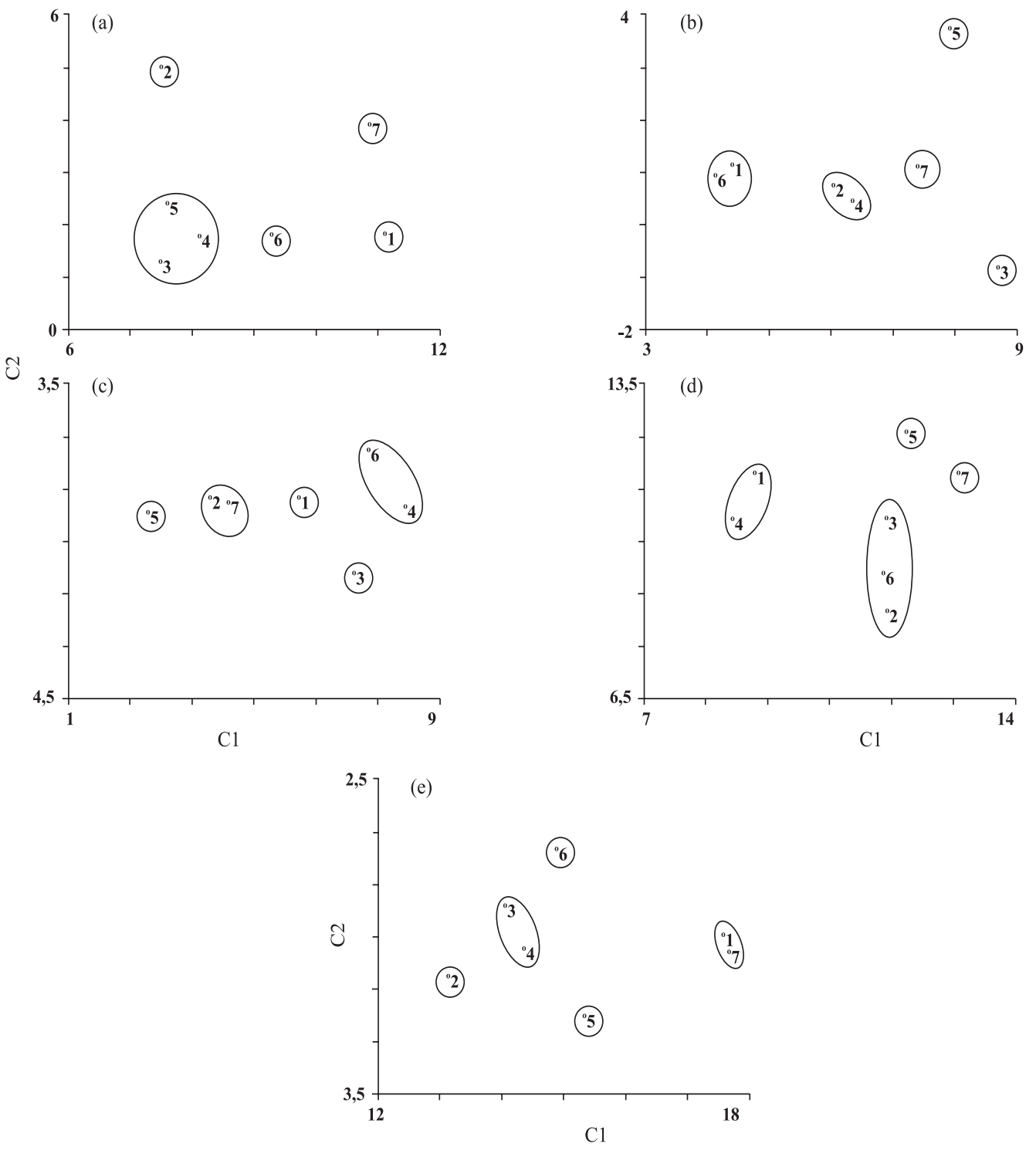

1: Pau-roxo; 2: Putumuju; 3: Arapati; 4: Arapaçu; 5: Claraíba; 6: Óleo-Comumbá; 7: Plantio Misto. C1: Primeiro componente principal; C2: Segundo componente principal.

Figura 1. Dispersão gráfica em relação aos dois primeiros componentes principais, com base nas variáveis de conteúdo de C, N, P, K, Ca e Mg na parte áerea (a), folhedo (b), serapilheira (c), solo (d) e solo + planta (E) de diferentes plantios florestais no sudeste da Bahia.

$80,0 \%$ da variância total (CP1 explicou $42,7 \%$ da variância total, CP2 33,2 \% e CP3 16,8 \%). Apenas P e $\mathrm{C}$ foram as principais variáveis na distinção dos solos entre os plantios florestais (Quadro 2). A claraíba e o plantio misto constituíram grupos individuais. O pauroxo foi similar ao arapaçu, enquanto o grupo de maior número de indivíduos foi formado pelo arapati, óleocomumbá e putumuju (Figura 1d).

Analisando os componentes principais, constatase que tanto no compartimento solo como nos três compartimentos da biomassa vegetal (parte aérea, folhedo e serapilheira), o P foi a variável que mais contribuiu na dissimilaridade entre os plantios florestais por estar estreitamente associado ao CP1 em todos os compartimentos analisados (Quadro 2).

$\mathrm{O}$ estoque total de $\mathrm{C}$ e nutrientes no sistema soloplanta (solo + parte aérea + serapilheira) variou amplamente entre os plantios florestais. Nos plantios puros, o estoque médio de $\mathrm{C}$ foi de $227.562 \mathrm{~kg} \mathrm{ha}^{-1}$ (CV 10,6\%); $7.273 \mathrm{~kg} \mathrm{ha}^{-1}$ (CV 4,7\%); P $60 \mathrm{~kg} \mathrm{ha}^{-1}$ (CV 27,2); K $644 \mathrm{~kg} \mathrm{ha}^{-1}$ (CV 22,0 \%); Ca $3.335 \mathrm{~kg} \mathrm{ha}^{-1}$ (CV 29,5\%); Mg $497 \mathrm{~kg} \mathrm{ha}{ }^{-1}$ (CV 17,0) (Quadro 1). O pauroxo, de maneira geral, apresentou os maiores estoques de $\mathrm{C}$ e nutrientes (solo + planta). O plantio misto diferiu em relação à média dos plantios puros para $\mathrm{C}+26,9 \% ; \mathrm{N}+20,3 \% ; \mathrm{P}+10,2 \% ; \mathrm{K}+16,8 \% ; \mathrm{Ca}-$ 
$1,9 \% ; \mathrm{Mg}+18,5 \%$. Tais resultados evidenciam a maior capacidade do plantio misto de acumular $\mathrm{C}$ e nutrientes em relação ao plantio puro. A variância total entre as coberturas florestais foi explicada em três componentes principais (CP1 explicou 54,6 \% da variância total, CP2 18,8 \% e CP3 17,5 \%). As variáveis estreitamente associadas ao $\mathrm{CP} 1$ foram $\mathrm{C}, \mathrm{K}, \mathrm{Mg}$ e N; o P mostrou associação ao CP2 e Ca ao CP3 (Quadro 2). Houve a formação de cinco grupos heterogêneos entre si. O arapati e o arapaçu formaram um grupo, e o pau-roxo e o misto outro grupo. O putumuju, a claraíba e o óleo-comumbá constituíram grupos individuais (Figura 1e).

\section{Ciclagem e balanço interno de nutrientes}

Para todos os nutrientes, o plantio misto apresentou maior intensidade de ciclagem bioquímica do que a média dos plantios puros. Elevadas taxas de retranslocação (valor negativo) de $\mathrm{P}$ e K ocorreram em todas as coberturas. Não houve aparentemente retranslocação de $\mathrm{Mg}$ no arapaçu, tampouco de $\mathrm{N}$ no pau-roxo, arapati, arapaçu e misto (valor positivo). $\mathrm{O}$ Ca apresentou baixa taxa de retranslocação (valor negativo) no pau-roxo, claraíba e misto (Quadro 5). Estes resultados evidenciam que a intensidade de ciclagem bioquímica variou de acordo com o nutriente, espécie e sistema de plantio. Para quase todos os tipos florestais, normalmente, o $\mathrm{N}$ apresenta altas taxas de retranslocação, ao contrário do Ca que se caracteriza por ter baixa e, ou, nenhuma mobilidade (Reis \& Barros, 1990; Gama-Rodrigues \& Barros, 2002; Zaia \& Gama-Rodrigues, 2004).

Para ciclagem biogeoquímica, o plantio misto foi superior à média dos plantios puros, à exceção de Ca. Em todas as coberturas florestais, a intensidade de ciclagem biogeoquímica de $\mathrm{Ca}$ foi positiva, indicando tendência de acumulação do elemento na serapilheira. A mesma tendência foi observada para Mg nos plantios de putumuju, arapaçu e óleo-comumbá. A maior taxa de mineralização (valor negativo) foi do K, seguido do $\mathrm{N}$ e $\mathrm{P}$ (Quadro 5). A intensidade de ciclagem biogeoquímica também variou dependendo do elemento, da espécie e do sistema de plantio.

Numa análise conjunta dos dois mecanismos de ciclagem avaliados, em ambos os sistemas de plantio, verifica-se, de maneira geral, para cada nutriente, que quanto maior a intensidade de ciclagem bioquímica menor a intensidade de ciclagem biogeoquímica. Todavia, os resultados do presente trabalho não revelaram, claramente, que a cobertura de maior intensidade de ciclagem bioquímica produziria serapilheira de baixa qualidade nutricional, por conseguinte menor intensidade de ciclagem biogeoquímica, em relação às demais coberturas. A claraíba, por exemplo, mostrou melhor qualidade nutricional foliar, do folhedo e da serapilheira que o pau-roxo; contudo, teve menor intensidade de ciclagem biogeoquímica para N, P e Mg (Quadros 4 e 5). Entre

Quadro 5. Variação percentual da concentração de nutrientes entre o folhedo (Fo) e as folhas da parte aérea (F) (ciclagem bioquímica) e entre a serapilheira foliar (S) e o folhedo (Fo) (ciclagem biogeoquímica) de diferentes coberturas florestais no sudeste da Bahia

\begin{tabular}{|c|c|c|c|c|c|}
\hline Cobertura & $\mathbf{N}$ & $\mathbf{P}$ & $\mathbf{K}$ & $\mathbf{C a}$ & Mg \\
\hline & \multicolumn{5}{|c|}{ Ciclagem bioquímica } \\
\hline Pau-roxo & $+68,8$ & $-41,0$ & $-77,3$ & $-28,3$ & $-21,9$ \\
\hline Putumuju & $-6,5$ & $-51,2$ & $-64,4$ & $+6,3$ & $-16,4$ \\
\hline Arapati & $+44,3$ & $-51,2$ & $-64,4$ & $+6,3$ & $-16,4$ \\
\hline Arapaçu & $+15,4$ & $-47,9$ & $-77,1$ & $+65,3$ & $+22,9$ \\
\hline Claraíba & $-6,2$ & $-62,6$ & $-60,0$ & $-8,4$ & $-19,3$ \\
\hline Óleo-comumbá & $-7,1$ & $-68,1$ & $-79,4$ & $+40,0$ & $-0,7$ \\
\hline Misto & $+10,3$ & $-67,0$ & $-73,0$ & $-32,1$ & $-27,2$ \\
\hline Capoeira & $+23,3$ & $-76,9$ & $-65,4$ & $-13,6$ & $-57,9$ \\
\hline \multirow[t]{2}{*}{ Floresta natural } & $+3,1$ & $-67,1$ & $-70,8$ & $-22,9$ & $-40,7$ \\
\hline & \multicolumn{5}{|c|}{ Ciclagem biogeoquímica } \\
\hline Pau-roxo & $-24,7$ & $-26,1$ & $-42,3$ & $+58,7$ & $-35,1$ \\
\hline Putumuju & $-34,1$ & $-38,1$ & $-62,5$ & $+29,7$ & $+18,8$ \\
\hline Arapati & $-22,7$ & $-39,5$ & $-59,5$ & $+60,3$ & $-25,0$ \\
\hline Arapaçu & $-22,3$ & $-24,0$ & $-36,6$ & $+20,2$ & $+4,7$ \\
\hline Claraíba & $-14,7$ & $-14,5$ & $-63,6$ & $+24,7$ & $-2,1$ \\
\hline Óleo-comumbá & $-5,3$ & $-17,4$ & $-30,6$ & $+49,1$ & $+3,5$ \\
\hline Misto & $-27,0$ & $-42,4$ & $-61,5$ & $+38,0$ & $-21,1$ \\
\hline Capoeira & $-25,8$ & $-23,3$ & $-60,8$ & $+22,6$ & $-14,0$ \\
\hline Floresta natural & $-3,0$ & $-17,4$ & $-64,6$ & $+19,5$ & $-22,1$ \\
\hline
\end{tabular}


os dois sistemas de plantio, o misto seria mais eficiente tanto para o ciclo bioquímico quanto para o biogeoquímico. Desse modo, o plantio misto, por combinar espécies que apresentariam interações complementares da ciclagem de nutrientes (ciclos bioquímicos e biogeoquímicos), seria o mais adequado para solos de baixa fertilidade.

A alta intensidade de ciclagem biogeoquímica (valores negativos) indica altas taxas de transferência relativa de $\mathrm{C}$ e nutrientes para o solo mediante $\mathrm{o}$ processo de decomposição e mineralização, e não necessariamente maior capacidade de melhorar a fertilidade do solo. Este é o caso do pau-roxo que mostrou maior intensidade de ciclagem de $\mathrm{P}$ que a claraíba, mas apresentou menor estoque do elemento no solo (Quadros 1 e 5). Isto foi devido, provavelmente, pelo fato de o pau-roxo ter acumulado maior quantidade de $\mathrm{P}$ na biomassa aérea e, ou, ter maior eficiência de absorção. Contudo, a ciclagem biogeoquímica de $\mathrm{P}$ no putumuju foi 2,6 vezes superior à da claraíba, porém as duas espécies apresentaram similar quantidade de $\mathrm{P}$ no solo e na biomassa aérea. Por outro lado, plantações de eucalipto e pinus em comparação com as espécies nativas apresentaram maior eficiência de aquisição e de retranslocação de nutrientes, produzindo serapilheira de baixa qualidade nutricional, e, em conseqüência, menor taxa de mineralização, ocasionando, assim, redução no nível de fertilidade do solo (O’Connell \& Sankaran, 1997; Gama-Rodrigues \& Barros, 2002).

Na ciclagem bioquímica, a variância total entre os plantios florestais foi explicada em três componentes principais (CP1 explicou 44,3 \% da variância total, CP2 31,6 \% e CP3 21,7\%). Apenas o Mg mostrou estreita associação ao $\mathrm{CP} 1$, enquanto o $\mathrm{P}$ e $\mathrm{K}$ apresentaram associação aos CP2 e CP3, respectivamente; já o $\mathrm{N}$ mostrou baixa associação $(<0,70)$ aos componentes principais (Quadro 2). O $\mathrm{Mg}$, portanto, foi a variável mais discriminante na avaliação da variação total entre os ciclos bioquímicos das diferentes coberturas florestais. Houve a formação de quatro grupos heterogêneos entre si, em que o grupo de maior número de indivíduos foi formado pelo putumuju, claraíba e misto. O pau-roxo e o arapati constituíram o segundo grupo, enquanto o arapaçu e o óleo-comumbá constituíram grupos individuais (Figura 2a). No ciclo biogeoquímico, dois componentes principais explicaram $80,0 \%$ da variância total (CP1 explicou 45,3 \% da variância total e CP2 35,1 \%). As variáveis que apresentaram estreita associação ao CP1 foram P, N e K (Quadro 2). Tanto o arapati e o misto quanto o arapaçu e a claraíba foram similares entre si. O pau-roxo, putumuju e óleo-comumbá constituíram grupos individuais (Figura 2b).

A dissimilaridade entre os plantios florestais variou de acordo com os compartimentos de estoque de $\mathrm{C} \mathrm{e}$ nutrientes no sistema solo-planta e os mecanismos de ciclagem (bioquímica e biogeoquímica). Não houve, portanto, padrão uniforme de comportamento, razão
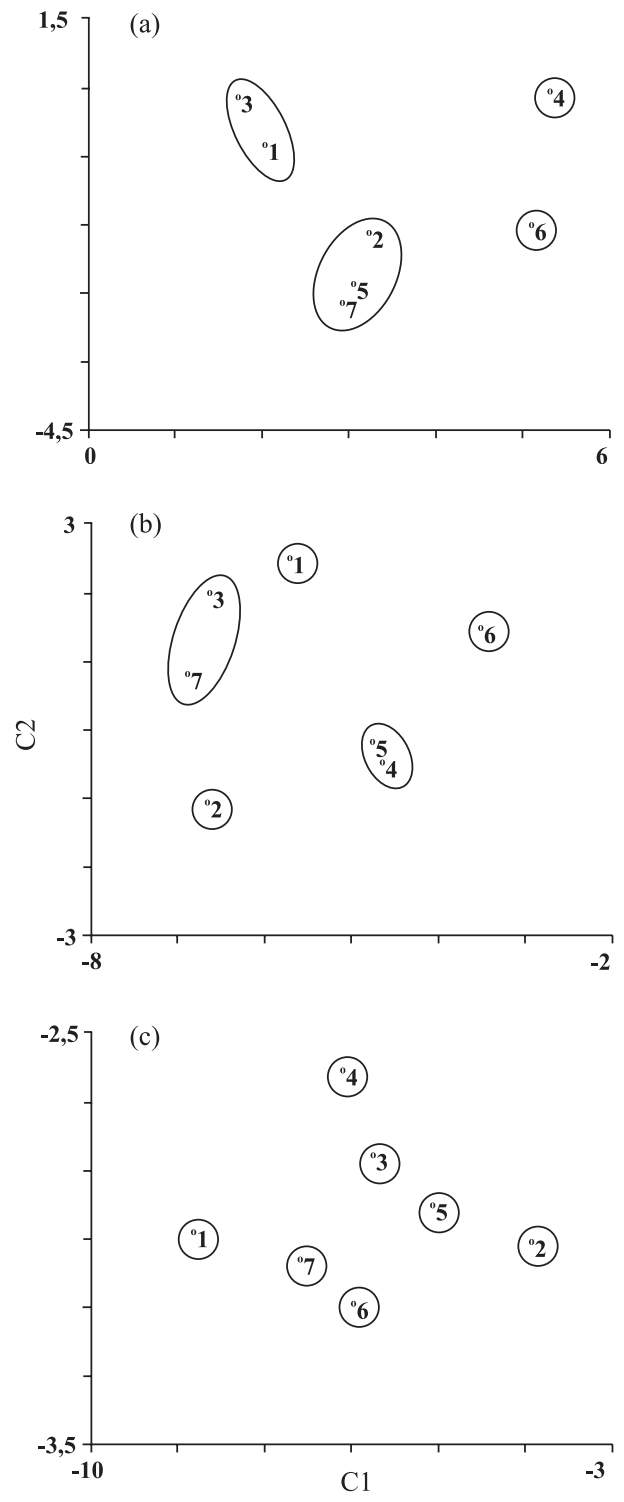

1: Pau-roxo; 2: Putumuju; 3: Arapati; 4: Arapaçu; 5: Claraíba; 6: Óleo-Comumbá; 7: Plantio Misto. C1: Primeiro componente principal; C2: Segundo componente principal.

Figura 2. Dispersão gráfica em relação aos dois primeiros componentes principais, com base nas variáveis de intensidade da ciclagem bioquímica (a) e biogeoquímica (b) de N, P, K, Ca e Mg e do balanço (c) de carbono e nutrientes de diferentes plantios florestais no sudeste da Bahia.

pela qual os números de grupos formados e os números e tipos de coberturas pertencentes de cada grupo não foram os mesmos para todos os compartimentos e ciclos avaliados. Assim, o plantio misto foi dissimilar em relação a todos os plantios puros apenas nos compartimentos de biomassa aérea, folhedo e solo (Figura 1a, b e d). 
O balanço interno de $\mathrm{C}, \mathrm{Pe} \mathrm{K}$ foi negativo em todas as coberturas florestais. Entretanto, para $\mathrm{N}$ o balanço foi positivo. O balanço de $\mathrm{Ca}$ foi positivo apenas para o arapaçu. Já o de $\mathrm{Mg}$ foi negativo somente no putumuju e óleo-comumbá (Quadro 6). O balanço mais negativo, em termos relativos, foi de $\mathrm{P}$, seguido de $\mathrm{Ke}$ Ca. O pau-roxo foi a espécie que apresentou o balanço mais negativo, especialmente para C, P e K. Para $\mathrm{Ca}$, o balanço mais negativo foi do putumuju e do óleocomumbá. A claraíba, de maneira geral, teve o balanço menos negativo. $\mathrm{O}$ plantio misto apresentou balanço próximo à média dos plantios puros. Isto indica que o plantio misto expressaria a contribuição média individual de cada espécie que compõe o sistema, representando uma situação intermediária em relação aos plantios puros. O balanço interno de nutrientes refletiu, em certo limite, o nível de fertilidade do solo. Quanto mais negativo o balanço menor o estoque de nutrientes no solo. Este é o caso do pau-roxo para $\mathrm{Pe}$ do putumuju para $\mathrm{Ca}$.

Houve total dissimilaridade entre os plantios florestais para o balanço interno de nutrientes, sendo necessários três componentes principais para explicar 80,0 \% da variância total (CP1 explicou $42,1 \%$ da variância total, $\mathrm{CP} 228,5$ \% e CP3 17,0 \%). O K, P e $\mathrm{C}$, por apresentarem estreita associação ao $\mathrm{CP} 1$, foram as variáveis que mais contribuíram na distinção dos plantios florestais; o Ca mostrou associação ao CP2 e $\mathrm{N}$ ao CP3 (Quadro 2). Os plantios foram distribuídos em sete grupos heterogêneos entre si. Isto indica que o balanço de nutrientes variou de acordo com a espécie e com o sistema de plantio (puro x misto) (Figura 2c). Os resultados também indicam que o balanço seria o método que melhor evidenciaria o grau de dissimilaridade entre os plantios florestais em relação aos estoques de cada compartimento do sistema soloplanta e os mecanismos de ciclagem de nutrientes.

\section{Plantio misto, capoeira e floresta natural}

\section{Estoque de carbono e nutrientes}

$\mathrm{Na}$ biomassa da parte aérea, o plantio misto foi superior à capoeira nos estoques de $\mathrm{C}(+2,1 \%), \mathrm{N}$
(+ 30,0 \%), P (+ 14,3\%) e Mg (+ 74,4\%); contudo, foi superior à floresta natural apenas para $\mathrm{P}(+19,1 \%)$ (Quadro 1). Comportamento análogo ocorreu no folhedo (Quadro 3). Na serapilheira acumulada, o plantio misto foi superior à capoeira apenas para $\mathrm{N}$ (+ 17,7\%) e $\mathrm{Mg}$ (+66,7\%); entretanto, em comparação à floresta natural, mostrou menores estoques para todos os elementos avaliados, à exceção de $\mathrm{Ca}$ e $\mathrm{Mg}$ no qual não houve praticamente diferenças entre essas coberturas. Apenas no solo, o plantio misto foi superior à capoeira e à floresta natural para todos os elementos avaliados (Quadro 1). Destacam-se as maiores quantidades de $\mathrm{P}(+200,0 \%)$ e de C (+ 100,3 \%) em relação à capoeira e à floresta natural, respectivamente.

\section{Ciclagem e balanço interno de nutrientes}

As três coberturas florestais mostraram semelhante padrão de comportamento na intensidade de ciclagem bioquímica. Houve retranslocação (valor negativo) para todos os elementos, à exceção de $\mathrm{N}$ (valor positivo). Essas coberturas também apresentaram o mesmo padrão de comportamento para o ciclo biogeoquímico; contudo, ocorreu tendência de acumulação de $\mathrm{Ca}$ (valor positivo) e de mineralização de N (valor negativo) (Quadro 5).

$\mathrm{O}$ balanço interno de $\mathrm{C}$ e nutrientes da capoeira $\mathrm{e}$ da floresta natural apresentou a mesma tendência do plantio misto. Para C, $\mathrm{P}, \mathrm{Ke} \mathrm{Ca}$, o balanço foi negativo, e positivo para N. Entretanto, apenas na floresta natural, o balanço de $\mathrm{Mg}$ foi negativo (Quadro 6). Os resultados indicam que o plantio misto tenderia a ter uma distribuição mais eqüitativa entre o solo e a vegetação para todos os elementos do que a capoeira e a floresta natural. Nessas coberturas naturais, por exemplo, o balanço de $\mathrm{C}$ foi bem mais negativo, em termos relativos, do que no plantio misto.

Para os estoques de $\mathrm{C}$ e nutrientes em cada compartimento do sistema solo-planta, dos ciclos bioquímicos e biogeoquímicos e do balanço interno avaliados, houve total dissimilaridade entre os

Quadro 6. Balanço de carbono e nutrientes de diferentes coberturas florestais no sudeste da Bahia

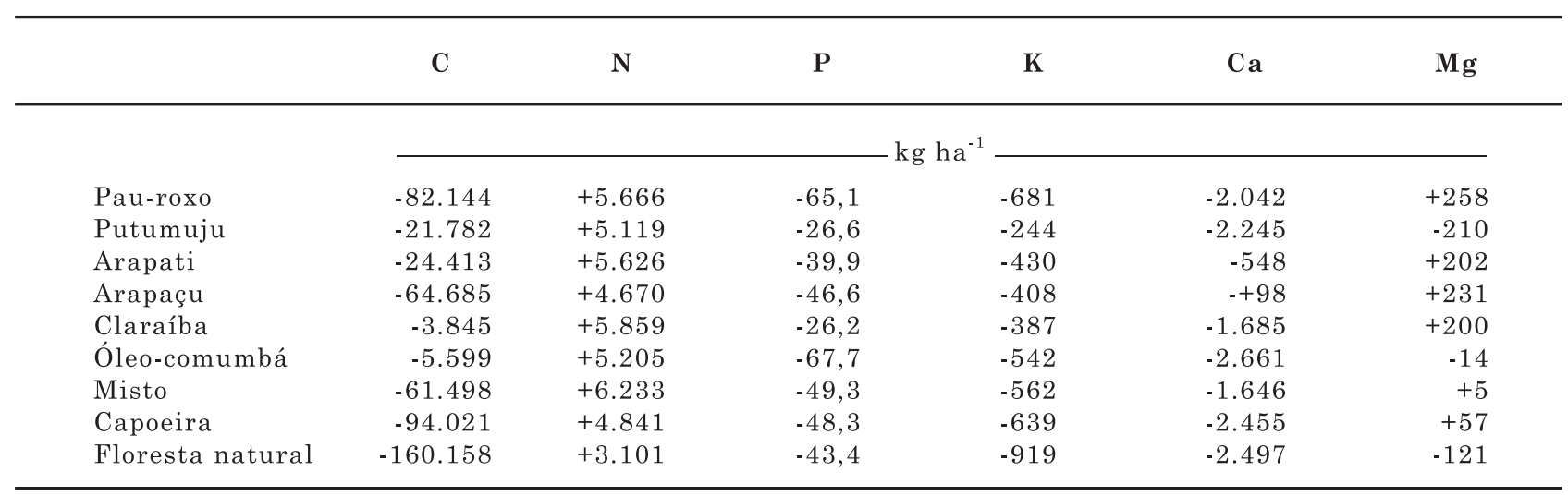


ecossistemas heterogêneos sempre com a formação de três grupos individuais (Figuras 3 e 4). O primeiro componente principal explicou de 62,0 a 90,0 \% da variância total entre as coberturas florestais. $\mathrm{O} \mathrm{P}$ e Ca foram as variáveis que mais contribuíram na dissimilaridade entre esses ecossistemas heterogêneos por estarem estreitamente associados ao CP1 em todos os compartimentos e ciclos analisados (Quadro 7).

$\mathrm{O}$ balanço interno negativo indica a baixa capacidade de suprimento de nutrientes do solo para a mesma produção de biomassa em rotações futuras. $\mathrm{O}$ balanço negativo de $\mathrm{C}$ revela a baixa estabilidade dessas coberturas florestais (Quadro 6). Esses resultados são corroborados por Fassbender (1993) para outras coberturas florestais na região tropical, nos quais o balanço negativo de $\mathrm{C}$ e nutrientes dá igualmente certa informação sobre o grau de adaptação da vegetação ao solo. Quando as reservas da vegetação são maiores que as do solo, pode-se concluir que o desenvolvimento do sistema radicular é muito pobre e que a vegetação se desenvolve "sobre o solo" e não "no solo", mediante a interação raiz-serapilheira. O ciclo da matéria orgânica, neste caso, localiza-se na serapilheira acumulada e os processos de produção e decomposição da matéria orgânica desempenham papel primordial no ciclo correspondente.
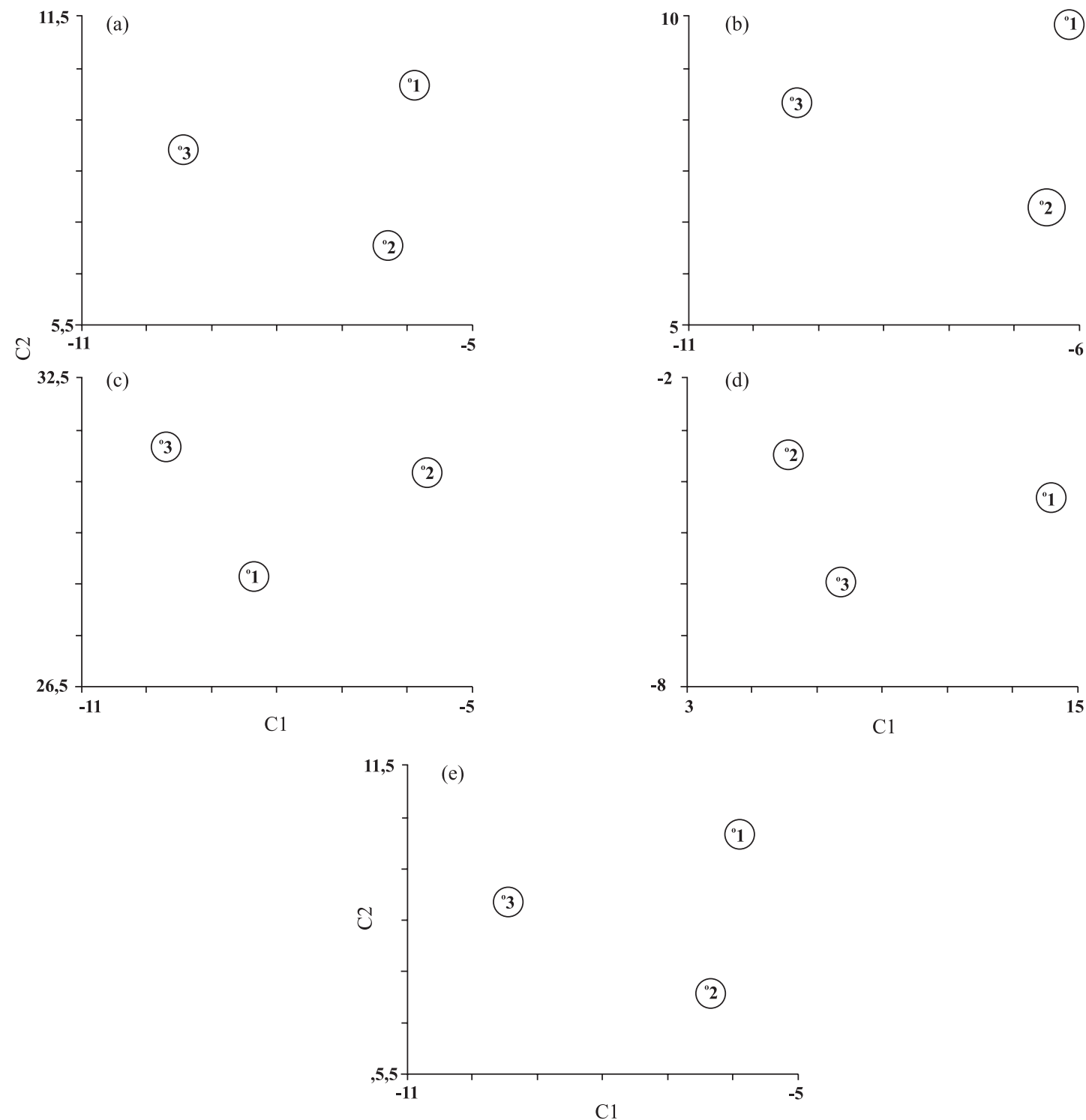

1: Plantio misto; 2: Capoeira; 3: Floresta natural. C1: Primeiro componente principal; C2: Segundo componente principal.

Figura 3. Dispersão gráfica em relação aos dois primeiros componentes principais, com base nas variáveis de conteúdo de C, N, P, K, Ca e Mg na parte áerea (a), folhedo (b), serapilheira (c), solo (d) e solo + planta (E) de diferentes coberturas florestais no sudeste da Bahia. 


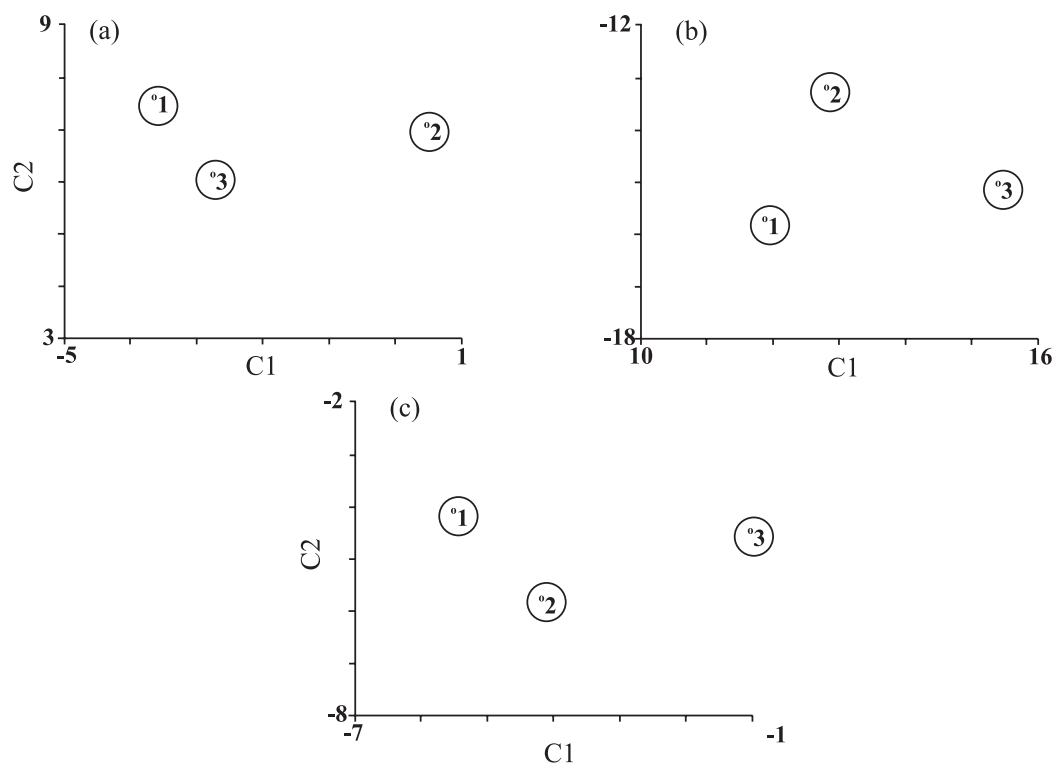

1: Plantio misto; 2: Capoeira; 3: Floresta natural. C1: Primeiro componente principal; C2: Segundo componente principal.

Figura 4. Dispersão gráfica em relação aos dois primeiros componentes principais, com base nas variáveis de intensidade da ciclagem bioquímica (a) e biogeoquímica (b) de N, P, K, Ca e Mg e do balanço (c) de carbono e nutrientes de diferentes coberturas florestais no sudeste da Bahia.

Quadro 7. Cargas relativas das diferentes variáveis associadas aos componentes principais (CP), nos compartimentos do sistema solo-planta, da ciclagem bioquímica e biogeoquímica e do balanço de $\mathrm{C}$ e nutrientes do plantio misto, capoeira e floresta natural. (Em negrito, cargas > 0,70 usadas para interpretar cada componente principal)

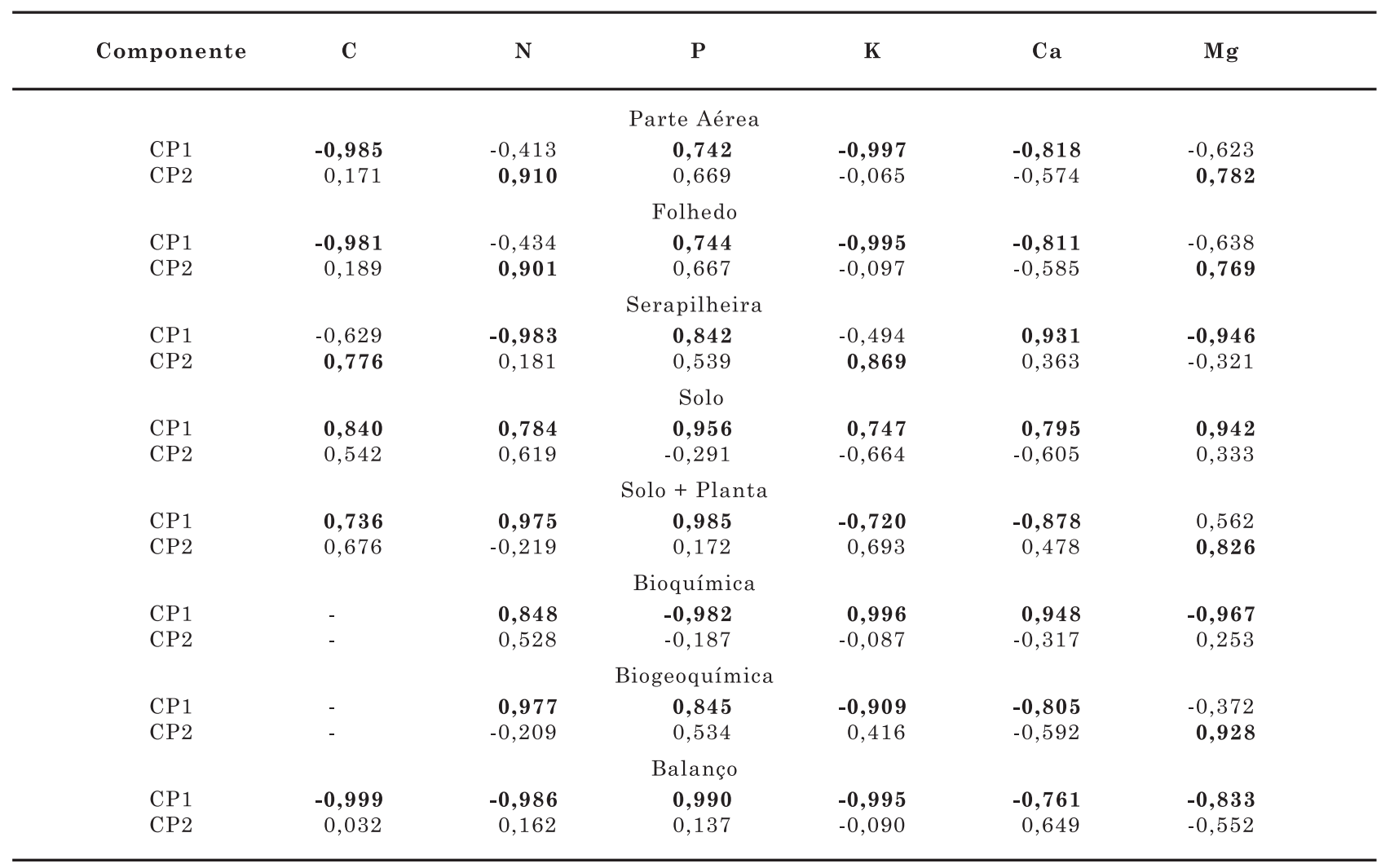


Em geral, o balanço de $\mathrm{C}$ em florestas naturais de terras baixas nos trópicos úmidos é negativo (Fassbender, 1985; Brown et al., 1994), estando, em média, cerca de $60 \%$ do $\mathrm{C}$ imobilizado na biomassa vegetal. Entretanto, o balanço de $\mathrm{N}$ total é positivo (Jordan, 1985; Fassbender, 1993). Os balanços de P, $\mathrm{K}$ e Ca são, normalmente, negativos e de Mg positivos, tanto para florestas naturais (Jordan, 1985; Fassbender, 1993; Brown et al., 1994) quanto para plantadas, particularmente a de eucalipto (Leite et al., 1998; Zaia \& Gama-Rodrigues, 2004; Cunha et al., 2005).

Os resultados dos mecanismos de ciclagem e do balanço de $\mathrm{C}$ e nutrientes, observados no presente trabalho, revelaram o potencial de uso desses mecanismos como um método adequado para avaliar a capacidade produtiva dos solos das coberturas florestais estudadas. Nesse sentido, o plantio florestal, especialmente em sistema misto, desde que seja adequadamente manejado e que considere a escolha das espécies de acordo com os seus atributos ecofisiológicos, seria mais eficiente que a técnica de regeneração natural para a recuperação e, ou, melhoria da qualidade do solo e produção sustentável.

\section{CONCLUSÃO}

1. $\mathrm{O} \mathrm{P}$ foi o nutriente que mais contribuiu na dissimilaridade entre o plantio puro e misto e entre o plantio misto e as florestas naturais não só no solo e na planta, como também no ciclo bioquímico e biogeoquímico e no balanço de nutrientes.

2. O balanço interno de carbono e nutrientes foi o método que melhor evidenciou o grau de dissimilaridade entre o plantio puro e misto, revelando a capacidade diferenciada dessas coberturas florestais para acumular e reciclar matéria orgânica e elementos minerais.

3. O plantio misto mostrou-se o sistema de produção florestal mais adequado para solos de baixa fertilidade em relação aos plantios puros, por proporcionar, simultaneamente, a maior eficiência da ciclagem bioquímica e biogeoquímica e os balanços mais equilibrados de carbono e nutrientes.

\section{LITERATURA CITADA}

ADAMS, A.M. \& ATTIWILL, P.M. Nutrient cycling and nitrogen mineralization in eucalypt forests of south-eastern Australia. I. Nutrient cycling and nitrogen turnover. Plant Soil, 92:319-339, 1986.

BATAGLIA, O.C.; FURLANI, A.M.C.; TEIXEIRA, J.P.F.; FURLANI, P.R. \& GALLO, J.R. Métodos de análise química de plantas. Campinas, Instituto Agronômico de Campinas, 1983. 48p. (Boletim Técnico, 78)
BRAGA, J.M. \& DEFELIPO, B.V. Determinação espectrofotométrica de fósforo em extrato de solo e material vegetal. R. Ceres, 21:73-85, 1974.

BROWN, S.; ANDERSON, J.M.; WOOMER, P.L.; SWIFT, M.J.; BARRIOS, E. Soil biological processes in tropical ecosystems. In: WOOMER, P.L. \& SWIFT, M.J., eds. The biological management of tropical soil fertility. Nairobi, TSBF, 1994. p.15-46.

CADIMA, Z.A. Condutividade hidráulica de um Oxisol (Harplothox) variação tabuleiro. R. Theobroma, 14:149175,1984

CRUZ, C.D. \& REGAZZI, A.J. Modelos biométricos aplicados ao melhoramento genético. Viçosa, MG, Universidade Federal de Viçosa, 1997. 390p.

CUNHA, G.M.; GAMA-RODRIGUES, A.C. \& COSTA, G.S. Ciclagem de nutrientes em Eucalyptus grandis W. Hill ex Maiden no norte fluminense. R. Árvore, 29:353-363, 2005.

EMPRESA BRASILEIRA DE PESQUISA AGROPECUÁRIA EMBRAPA. Centro Nacional de Pesquisa de Solos. Manual de métodos de análise de solo. 2.ed. Rio de Janeiro, 1997. 212p.

FASSBENDER, H.W. Ciclos da matéria orgânica e dos nutrientes em ecossistemas florestais dos trópicos. In: CABALA-ROSAND, P., ed. Reciclagem de nutrientes e agricultura de baixos insumos nos trópicos. Ilhéus, CEPLAC, 1985. p.203-230.

FASSBENDER, H.W. Modelos edafologicos de sistemas agroforestales. Turrialba, CATIE, 1993.491p.

GAMA-RODRIGUES, A.C. \& BARROS, N.F. Ciclagem de nutrientes em floresta natural e em plantios de eucalipto e de dandá no sudeste da Bahia, Brasil. R. Árvore, 26:193207, 2002 .

GAMA-RODRIGUES, A.C.; BARROS, N.F. \& COMERFORD, N.B. Biomass and nutrient cycling in pure and mixed stands of native tree species in southeastern Bahia, Brazil. R. Bras. Ci. Solo, 31:287-298, 2007.

GAMA-RODRIGUES, A.C.; BARROS, N.F. \& SANTOS, M.L. Decomposição e liberação de nutrientes do folhedo de espécies florestais nativas em plantios puros e mistos no sudeste da Bahia. R. Bras.Ci. Solo, 27:1021-1032, 2003.

GOMES, J.B.V.; CURI, N.; MOTTA, P.E.F.; KER, J.C.; MARQUES, J.J.G.S.M. \& SCHULZE, D.G. Análise de componentes principais de atributos físicos, químicos e mineralógicos de solos do bioma Cerrado. R. Bras.Ci. Solo, 28:137-154, 2004.

JORDAN, C.F. Nutrient cycling in tropical forest ecosystems. Chichester, John Wiley \& Sons, 1985. 190p.

LEÃO; A.C. \& MELO, A.A.O. Características morfológicas, físico-químicas e mineralógicas dos solos da Estação Ecológica do Pau-Brasil, Porto Seguro, Bahia. Agrotrópica, 2:105-112, 1990.

LEITE, F.P.; BARROS, N.F.; NOVAIS, R.F. \& FABRES, A.S. Acúmulo e distribuição de nutrientes em Eucalyptus grandis sob diferentes densidades populacionais. R. Bras. Ci. Solo, 22:419-426, 1998. 
MORI, S.A. \& SILVA, L.A.M. O herbário do Centro de Pesquisas do Cacau em Itabuna, Brasil. Ilhéus, CEPLAC/CEPEC, 1980. 8p.(Boletim Técnico, 78)

NAIR, P.K.R. The role of soil science in the sustainability of agroforestry systems: Eliminating hunger and poverty. In: GAMA-RODRIGUES, A.C.; BARROS, N.F.; GAMARODRIGUES, E.F.; FREITAS, M.S.M.; VIANA, A.P.; JASMIN, J.M.; MARCIANO, C.R. \& CARNEIRO, J.G.A., eds. Sistemas agroflorestais: Bases científicas para o desenvolvimento sustentável. Campos dos Goytacazes, Universidade Estadual do Norte Fluminense Darcy Ribeiro, 2006. p.203-216.

O'CONNELL, A.M. \& SANKARAN, K.V. Organic matter accretion, decomposition and mineralization. In: NAMBIAR, E.K.S. \& BROWN, A.G., eds. Management of soil, nutrients and water in tropical plantation forests. Canberra, ACIAR, 1997. p.443-480.

REIS, M.G.F. \& BARROS, N.F. Ciclagem de nutrientes em plantios de eucalipto. In: BARROS, N.F. \& NOVAIS, R.F., eds. Relação solo-eucalipto. Viçosa, MG, Folha de Viçosa, 1990. p.265-302.

SWITZER, G.L. \& NELSON, L.E. Nutrient accumulation and cycling in loblolly pine (Pinus taeda L.) plantation ecosystems: The first twenty years. Proc. Soil Sci. Soc. Am., 36:143-147, 1972.
TAYLOR, B.R.; PARKINSON, D. \& PARSONS, W.F.J. Nitrogen and lignin content as predictors of litter decay rates: A microcosm test. Ecology, 70:97-104, 1989.

TER BRAAK, C.J.F. Canonical correspondence analysis: A new eigenvector technique for multivariate direct gradient analysis. Ecology, 67:1167-1179, 1986.

van WESEMAEL, B. Litter decomposition and nutrient distribution in humus profiles in some mediterranean forests in southern Tuscany. For. Ecol. Manag., 57:99114, 1993.

VELOSO, H.P.; RANGEL FILHO, A.L.R. \& LIMA, J.C.A. Classificação da vegetação brasileira adaptada a um sistema universal. Rio de Janeiro, IBGE, 1991. 124p.

VINHA, S.G. \& LOBÃO, D.E.V.P. Estação ecológica do PauBrasil, Porto Seguro, Bahia. Ilhéus, CEPLAC/CEPEC, 1989. $40 \mathrm{p}$

WICK, B.; TIESSEN, H. \& MENEZES, R. Land use changes following the conversion of the natural vegetation into silvo-pastoral systems in semi-arid NE Brazil. Plant Soil, 222:59-70, 1998.

ZAIA, F.C. \& GAMA-RODRIGUES, A.C. Ciclagem e balanço de nutrientes em povoamentos de eucalipto na região norte fluminense. R. Bras. Ci. Solo, 28:843-852, 2004. 